\title{
Shared Partisanship, Household Norms and Turnout: Testing a Relational Theory of Electoral Participation
}

\author{
EDWARD FIELDHOUSE AND DAVID CUTTS*
}

\begin{abstract}
Previous research shows that the household context is a crucial source of influence on turnout. This article sets out a relational theory of voting in which turnout is dependent on the existence of relational selective consumption benefits. The study provides empirical tests of key elements of the proposed model using household survey data from Great Britain. First, building on expressive theories of voting, it examines the extent to which shared partisan identification enhances turnout. Secondly, extending theories of voting as a social norm, it tests whether the civic norms of citizens' families or households affect turnout over and above the social norms of the individual. In accordance with expectations of expressive theories of voting, it finds that having a shared party identification with other members of the household increases turnout. It also finds that the civic duty of other household members is important in explaining turnout, even when allowing for respondent's civic duty.
\end{abstract}

A growing body of research shows that the household context is a powerful source of influence on turnout. ${ }^{1}$ For example, in Britain the probability that a citizen living with a voter will also vote is as high as 90 per cent, compared to only 10 per cent for a citizen living with a non-voter. ${ }^{2}$ Building on early work from the Columbia school, which highlighted the role of social influences on electoral behaviour, ${ }^{3}$ and more recent work on social network effects, the social transmission of messages ${ }^{4}$ and interpersonal mobilization, ${ }^{5}$ this article sets out a relational theory of voting. We provide preliminary empirical tests of the key elements of the proposed model using data from Great Britain.

Central to our approach is an understanding of turnout as a socially embedded activity. ${ }^{6}$ The dominant view in social models of participation is that social intimates grow more alike through long-term processes of socialization ${ }^{7}$ and interpersonal influence. ${ }^{8}$ We argue that the strong interdependence of voting in families (and other close-knit groups) arises because socially connected people motivate each other to vote at election time, either deliberately or otherwise, and these short-term influences can have lasting effects through social leaning and habituation.

* School of Social Sciences, University of Manchester (email: ed.fieldhouse@ manchester.ac.uk); Department of Politics, Languages and International Relations, University of Bath (email: djc54@bath.ac.uk). Professor Fieldhouse's involvement in this research was supported by ESRC research grant ES/L005166/1. Data replication sets are available at http://dataverse.harvard.edu/dataverse/BJPolS and online appendices are available at http://dx.doi.org/doi:10.1017/S0007123416000089.

1 Zuckerman, Dasovic, and Fitzgerald 2007.

2 Cutts and Fieldhouse 2009.

3 Berelson, Lazarsfeld, and McPhee 1954; Lazarsfeld, Berelson, and Gaudet 1944.

4 Bond et al. 2012.

5 Huckfeldt and Sprague 1995; McClurg 2003; Rosenstone and Hansen 1993; Zuckerman 2007. For a discussion of using experimental designs specifically related to the household, see Nickerson 2008; Sinclair 2012.

6 Sinclair 2012.

7 Jennings and Niemi 1981.

${ }^{8}$ Huckfeldt and Sprague 1995. 
Voters take into account the norms and behaviour of their reference group, as well as their personal costs and benefits. The influential role played by intimates means that turning out to vote is highly dependent on whether the people they live with are voters or not.

Below we outline our social-relational theory of turnout, which emphasizes external-selective consumption motivations including normative and symbolic elements. We identify two complimentary phenomena that help explain the turnout decision in general and household patterns of turnout in particular. First, building on expressive theories of voting, ${ }^{9}$ we examine the extent to which shared partisan identification might enhance turnout. Secondly, extending theories of voting as a social norm, ${ }^{10}$ we test whether the civic norms of citizens' families or households affect turnout over and above the social norms of the individuals themselves.

\section{MOTIVATIONS TO VOTE: WHY TURNOUT IS A SOCIAL PHENOMENA}

Social theories of voting commonly identify two crucial processes ways in which social networks influence turnout. First, over the long term, citizens who are socially connected grow more alike through socialization processes. ${ }^{11}$ Secondly, in the short term, connected citizens influence each other's attitudes and behaviour through interpersonal influence and mobilization. ${ }^{12}$ While these processes are crucial to understanding voter turnout, they do not explain why people vote, only how citizens may influence each other. We argue that the underlying motivations - that are learned through interpersonal influence and socialization - are themselves based, in part, on social relationships.

Plenty of scholars have incorporated group-based interests and social influence into theories of participation. ${ }^{13}$ In group-based models, voters' interests are in some way dependent on their membership of groups or networks, and members of those networks have greater incentives to vote compared to isolated individuals. Interaction within social networks can reduce information costs, ${ }^{14}$ determine relational benefits, ${ }^{15}$ and determine the costs and benefits of fulfilling social norms. ${ }^{16}$ In practice, this means that the turnout decision is, in part, a function of whether others in their social circle also vote. The idea of the conditional voter naturally leads to a prediction that voting (or the intention to vote) may spread though social networks leading to voting 'cascades' and bandwagon effects. ${ }^{17}$

In order to disentangle the multiple ways in which social factors can influence turnout, we disaggregate the fundamental motivations of voting and then identify the social dimension of each component. There are three main types of underlying motivations to vote. First, instrumental motivations reflect outcome-related benefits and costs-in other words, the expected utility derived from a preferred candidate or party being elected. Following minimal rational choice theories, this utility is derived from voters' policy preferences and candidates' policy positions. ${ }^{18}$ Secondly, symbolic motivations stem from the expressive benefits derived

9 Brennan and Lomasky 1993; Schuessler 2000.

10 Coleman 1990

11 Jennings and Niemi 1981.

12 Huckfeldt and Sprague 1995; Rosenstone and Hansen 1993.

13 Abrams, Iversen, and Soskice 2011; Knack 1992; McClurg 2003; Morton 1991; Rosenstone and Hansen 1993; Sinclair 2012.

14 Converse 1962

15 Uhlaner 1989.

16 Knack 1992.

17 Fowler 2005; Rolfe 2012.

18 Downs 1957; Riker and Ordeshook 1968. 
TABLE $1 \quad$ A Classification of Turnout Motivations

\begin{tabular}{|c|c|c|}
\hline & Outcome-related costs and benefits & Selective consumption costs and benefits \\
\hline \multirow[t]{2}{*}{$\begin{array}{l}\text { Egoist or } \\
\text { individual }\end{array}$} & $\begin{array}{l}\text { Expected utility (Downs 1957); } \\
\text { Satisficing (Bendor et al. 2003) }\end{array}$ & $\begin{array}{l}\text { Self-expression/intrinsic pleasures of } \\
\text { voting (Fiorina 1976) }\end{array}$ \\
\hline & Type: instrumental & Type: symbolic, instrumental \\
\hline \multirow[t]{2}{*}{ Internal social } & $\begin{array}{l}\text { Altruism (Goodin and Roberts 1975); } \\
\text { rule-utilitarian voter (Harsanyi 1980) }\end{array}$ & $\begin{array}{l}\text { Personal normative beliefs - civic duty } \\
\text { (Blais 2000) }\end{array}$ \\
\hline & Type: instrumental & Type: normative \\
\hline \multirow[t]{2}{*}{$\begin{array}{l}\text { External social } \\
\text { (relational) }\end{array}$} & $\begin{array}{l}\text { Group pivotal voter/sufficiency model } \\
\text { (Schelling 1978); relational benefits } \\
\text { (Uhlaner 1989) }\end{array}$ & $\begin{array}{l}\text { Subjective/injunctive norms - social } \\
\text { approval/disapproval (Gerber, Green } \\
\text { and Larimer 2010); Expressive voting/ } \\
\text { social identity (Schuessler 2000); } \\
\text { Companion effects (Fieldhouse and } \\
\text { Cutts 2012) }\end{array}$ \\
\hline & Type: instrumental & $\begin{array}{l}\text { Type: symbolic, normative and } \\
\text { instrumental }\end{array}$ \\
\hline
\end{tabular}

from supporting a particular candidate, which are reserved for those who participate. ${ }^{19}$ Thirdly, normative motivations reflect the social norms of voting (for example, civic duty) and the associated sanctions for non-compliance. ${ }^{20}$

Together with the cost of voting, these sets of motivations provide a micro-foundation for a relational model of turnout. Each of these types of motivation may be organized according to whether they depend on the election outcome, and whether they are individual (egocentric), socially motivated but internalized or externally motivated (relational) (Table 1). Individual or egocentric motivations are those solely driven by personal benefits or objectives. Internal social motivations are those that depend on considering the interests of others, but do not require social interaction, because the relevant attitudes or norms are internalized (for example, ethical voting). In other words, these motivations constitute an expression of what the individual thinks they ought to do. In social psychology these are sometimes referred to as personal normative beliefs. ${ }^{21}$ The widely used notion of (the personal sense of) civic duty belongs in this category. In contrast we consider external or relational motivations as those that depend on direct knowledge of the behaviour or attitudes of others or some actual or anticipated social interaction or transaction. These include both what social psychologists refer to as behavioural (or descriptive) norms (what the individual thinks others actually do) and normative expectations or subjective norms (what the individual believes referents think she should do). These are not necessarily manifested in the expressed personal normative beliefs of the individual but may be revealed by responses in behaviour. For example, the knowledge that a social intimate might disapprove of abstention may not be reflected in an individual's belief in the duty of voting, but may still affect his turnout behaviour. This subtle but important distinction between social motives that are internalized and those that require social interaction underpins the relational theory of turnout and drives the hypotheses tested in this article. Crucially, the strength of these relational motivations to vote is largely dependent on the number

19 Brennan and Lomasky 1993; Schuessler 2000.

20 Knack 1992.

21 Bicchieri 2015. 
of other people who vote in the citizen's social network, particularly among family, friends and acquaintances who share a partisan affiliation.

Table 1 denotes how the three types of motivation described above (instrumental, normative and symbolic) map onto the intersection of the individual-social and outcome-process dimensions of the turnout decision. Unlike previous approaches, which have focused largely on the group aspects of outcome-related motives ${ }^{22}$ and on internalized social norms, especially civic duty, ${ }^{23}$ we make the case for incorporating relational-selective consumption motivations into a relational theory of voting. In this article we focus on two key components of these relational consumption benefits:

(1) Norms of voting - shared personal beliefs about desirable behaviour enforced through the process of social approval and disapproval. These are most influential when applied by family members and close intimates.

(2) Expressive benefits - the benefits to voters of expressing their views and thereby identifying with a social group that they regard as desirable.

There is also a social dimension of the costs of voting. Costs may be reduced by sharing the experience of voting, for example attending the polling station together or sharing information about candidates. Moreover, voters may also use the decisions of intimates as a heuristic by imitating the turnout behaviour of referents whose opinions they respect, thus saving cognitive processing and information costs. However, while we include a simple indicator of the costs of voting in the empirical models presented below, for data availability reasons we do not test this aspect of the theory in this article.

\section{Consumption Benefits, Social Norms and Civic Duty}

In order to overcome the paradox of voting and 'free-rider' problems, Riker and Ordeshook extended Downs' model of voting to include the notion of citizen duty and other benefits that are not dependent on the outcome (the D term). ${ }^{24}$ Crucially, these selective benefits are only enjoyed by electors who actually vote, thereby sidestepping the collective action problem. Fiorina described these more generally as consumption benefits, in contrast to investment (outcome-related) benefits. Because consumption benefits, such as civic duty, are not dependent on the outcome of the election, they are not discounted by the factor probability $(\mathrm{P})$ of any vote being decisive. ${ }^{25}$ As it is widely believed that the costs of voting are non-negligible, albeit low, this places considerable emphasis on the D term. ${ }^{26}$ Despite its importance in explaining individual-level turnout, the concept of civic duty as an explanation for voting behaviour has generated considerable criticism. There is clear evidence that voters around the world agree that citizens have the duty to vote. For example, Blais reports that more than 90 per cent of citizens of two Canadian provinces agree that 'it is the duty of every citizen to vote', ${ }^{27}$ while in the United States in 2000 the proportion was over 70 per cent. ${ }^{28}$

Whereas research consistently shows that civic duty is correlated with turnout, others have pointed out that the explanation is little more than tautology. Including civic duty simply serves

${ }^{22}$ Morton 1991; Uhlaner 1989.

${ }^{23}$ Knack 1992.

${ }^{24}$ Riker and Ordeshook 1968.

${ }^{25}$ Fiorina 1976.

${ }^{26}$ Aldrich 1993.

${ }^{27}$ Blais 2000 .

${ }^{28}$ Blais and Achen 2010. 
to move the puzzle from why people vote to why people believe it is a duty to vote. ${ }^{29}$ Coleman outlines a general theory of the demand and realization of effective norms that can be applied to voting that avoids this problem. According to Coleman, citizens forego their right to determine their own action (whether or not to vote) in order to satisfy the demand for a norm of voting. ${ }^{30}$ The demand arises due to the externalities that are incurred if others collectively decide not to conform (that is, to abstain). These externalities might include the breakdown of democracy or extremist candidates being elected by a small number of votes. Beneficiaries of the norm may enforce compliance though the use of sanctions including social approval or disapproval, or in a more serious breach ostracism and social rejection. Norms are said to be internalized when external sanctioning becomes unnecessary, and the individual develops an internal sanctioning system of their own that discourages departure from the norm (for example, a sense of duty).

A number of predictions flow from this that are consistent with the empirical evidence on voting. One is that when individuals are removed from social networks that encourage voting, they will be less likely to vote. Residential mobility (and a subsequent weakening of social networks) is often found to be negatively related to turnout. ${ }^{31}$ A second prediction is that an individual embedded in social networks in which the norm of voting is less prevalent (or has as contacts with others who are not norm holders) will be less likely to conform. Thirdly, get-out-the-vote experiments using communication strategies aimed at manipulating social pressures have exhibited much greater mobilization effects than conventional rational or civic appeals. ${ }^{32}$ In their review of social pressure experiments, Green and Gerber argue that calling attention to past non-voting is particularly effective, as is the threat of 'shaming' non-compliers. ${ }^{33}$ They find that it is unnecessary to persuade electors of the importance of civic duty; it is sufficient to draw attention to the fact that their participation (or lack thereof) is being observed. Similarly, Abrams, Iversen and Soskice find support for a model of turnout based on the influence of social pressures within informal social networks, in which socially embedded individuals respond to the effect of voting on their social standing. ${ }^{34}$ Knack argues that declining social connectedness may be responsible for the declining turnout through the weakening of social pressures. $^{35}$

As noted above, in order to differentiate the relational selective consumption benefits from those that are internally motivated, it is necessary to distinguish between personal normative beliefs (such as civic duty), behavioural norms (perceptions of whether referents actually vote) and subjective normative expectations. This is reflected in our hypotheses and model specification below.

\section{Expressive Voting and Social Identity}

While the D term has commonly been equated with civic duty or norms of voting, the idea of voting as an act of consumption can also be extended to expressive theories of voting. ${ }^{36}$ As with civic duty, according to the expressive logic, voting is an act of expression rather than of investment. Expressive voters derive benefits from taking part in an election, or more

29 Barry 1970.

30 Coleman 1990.

31 Dowding, John, and Rubenson 2012.

32 Gerber, Green, and Larimer 2010; Panagopolous 2010.

33 Green and Gerber 2010.

34 Abrams, Iversen, and Soskice 2011.

35 Knack 1992.

36 Brennan and Lomasky 1993. 
specifically from giving their support to a particular candidate or party, like a football fan gains pleasure from supporting his team. Voters enjoy benefits from expressing their views and thereby identifying with a social group they regard as desirable. The idea of voting as an expression of social identity is consistent with research on partisanship, which likens the sense of belonging to a political party to other social identities based on belonging to a particular ethnic or religious group, social class or political cause. ${ }^{37}$ By this account, voting is an act of identification - that is, it is about 'being' rather than 'doing' ${ }^{38}$ Thus expressive voting reflects the voter's social identity, and the expressive benefits derived vary according to the number and identity of other supporters of that candidate. In short, as the number of other like-minded voters supporting the same candidate increases, so too do the expressive benefits enjoyed by the voter.

The amount and character of support for a candidate may be partially gleaned from mass media (such as opinion polls) and partly from social networks. Even though expressive motivations could theoretically exist for socially isolated individuals, the expression of approval or disapproval for a candidate will have greater resonance if expressed as part of a group. ${ }^{39}$ Expressive benefits stem from the satisfaction derived from being part of a group of like-minded voters, and expressing their opinion. According to Schuessler, it is not necessary to know other supporters personally, but simply to regard the group in a positive way. Moreover, in this account expressive voting matters not only in public but also in private. ${ }^{40}$ Sinclair suggests that citizens take cues from friends and family rather than from society at large. ${ }^{41}$ We hypothesize that the shared experience of supporting a party that close friends or family also support will enhance the expressive benefits. If voting is about 'being' rather than 'doing', then 'being' a Democrat or a Republican is best enjoyed with social intimates who share that affiliation. In this sense, expressive voting is relational as opposed to simply 'social' (as depicted in Table 1 above). By explicitly linking expressive benefits to social identity theory, Schuessler provides a plausible micro foundation for why people vote, and at the same time, by implication, why turnout clusters within social networks and households. ${ }^{42}$

\section{HYPOTHESES}

\section{Relational Factors: Household Norms of Voting}

Following from the discussion above, social norms are relational in so far as friends, family, colleagues and other acquaintances may enforce them (for example, by voicing approval/ disapproval or withdrawing respect). This small personal network of family members and close intimates, whose opinion and approval is valued, often determines an individual's intention to vote. While it is not possible to gauge from individual-level survey data the extent to which norms are internalized vs. dependent on social interactions (that is, the extent to which they are relational), we are able to use household hierarchical data to test whether the norms of intimates are relevant beyond those of the individual. As Knack notes, 'voter participation is a function of one's own sense of duty, of the strength of duty of one's family, friends'. ${ }^{43}$ Thus normative relational motivations can be measured by the personal normative beliefs of a citizen's social intimates (measured by household members' conceptions of civic duty) and, as indicated above,

${ }^{37}$ Green, Palmquist, and Schickler 2002.

${ }^{38}$ Schuessler 2000.

${ }^{39}$ Franklin 2004.

${ }^{40}$ Schuessler 2000.

${ }^{41}$ Sinclair 2012.

42 Schuessler 2000.

${ }^{43}$ Knack 1992, 12. 
may not necessarily be manifested in the respondent's own personal normative beliefs (personal civic duty), but may be reflected in their voting decision. If household relational factors are not important, then the civic duty of others should have no additional impact on the probability of voting after allowing for the civic duty of the respondent and the impact of descriptive (or 'behavioural') norms (measured by the perception that 'most people around here usually vote in general elections'). However, if the civic duty of others does have an independent impact, then this suggests that social norms also have a relational component. This gives rise to our first hypothesis:

HYPOTHESIS 1: Household civic duty will have an independent and additional influence on voter turnout after allowing for individual-level civic duty and descriptive norms of voting.

\section{Relational Factors: Expressive Motives and Shared Partisanship}

Using similar reasoning, to operationalize our conceptualization of relational expressive voting, we employ a measure of whether or not party identification is shared with other members of the household. Following the discussion above, express motivations will be enhanced if citizens share a partisan identification with their social intimates. This leads to our second hypothesis:

HYPOTHESIS 2: Citizens who share a party identification with other members of their household will be more likely to vote than those who are the only party identifier in the household, or those whose fellow household members identify with a different party.

\section{DATA AND METHODS}

Our initial testing of our theory draws on data from Great Britain. From the perspective of studying turnout, the 2010 British general election is unremarkable with an overall turnout rate of 65 per cent. However, it is a useful laboratory for testing our relational model of voting due to the availability of high-quality household panel data that include most of the indicators we need to operationalize our model. More specifically, these data are from the UK household longitudinal survey dataset 'Understanding Society' (USoc). Using multi-stage survey designs with stratification and clustering, it provides nationally representative data at the individual and household levels across a range of substantive areas. ${ }^{44}$ We use data from Wave 2 of USoc because it contains a political engagement module that corresponds to the UK 2010 general election and complements the other politics modules from this wave of the USoc panel. However, this political engagement module is only asked of a subsample of respondents. Our main sample consists of 8,337 individuals who were nested in 5,101 households, including 2,532 single-person households.

\section{Model Specification}

The hierarchical nature of the sample suggests that simultaneous modelling of individual and household variation (known as hierarchical or multilevel modelling) is the most appropriate model specification. This provides a framework for exploring how relationships vary across hierarchical structures, whether these are natural or introduced in the sample design. Our model has individuals at level 1 nested within households at level 2. The model has two parts: (1) a fixed

44 For more details, see https://www.understandingsociety.ac.uk. 
part that contains estimates of the average relationship between vote intention and the predictor variables across households and individuals and (2) a random part that estimates the size of the between-household variation relative to the within-household, between-individual variation. ${ }^{45}$ Because we are interested in turnout as a binary outcome, a multilevel logistic regression model is specified. It is possible to illustrate the two-level model for a binary outcome using a single predictor variable in the following way. Given that our data consist of individuals (level 1) grouped into households (level 2), we observe $\mathrm{y}_{i j}$, which is a binary response (vote intention) for individual $i$ in household $j, \beta_{0}$ is the intercept, $x i j$ is a predictor variable at the individual level and $\beta_{1}$ is its effect. The probability of the response (vote intention) is equal to 1 as $\mathrm{p}_{i j}=\operatorname{Pr}\left(\mathrm{y}_{i j}=1\right)$, where $\mathrm{p}_{i j}$ is modelled using the logit link function. ${ }^{46} \mathrm{We}$ assume that the binary outcome $\mathrm{y}_{i j}$ has a Bernoulli distribution. The equation can therefore be written as follows:

$$
\log \left[\mathrm{p}_{i j} /\left(1-p_{i j}\right)\right]=\beta_{0}+\beta_{1 \mathrm{X}_{i j}}+\mathrm{u}_{j},
$$

where $u_{j}$ is the random effect at level 2 (household level) and is assumed to follow a normal or Gaussian distribution, which is conventionally summarized by the between-household variance term.

Conditional on $u_{j}$, it is assumed $\sigma_{u 0}^{2}$ that $y_{i j} s$ are independent. ${ }^{47}$ All the multilevel models were fitted using MLwiN 2.26 using the conventional penalized quasi-likelihood estimation method.

\section{Dependent Variable: Using Vote Intention}

It is not only attitudinal interdependence that may create similarity of intention, but also behavioural cues ('voting together'). Because USoc only collected data on motivations for participation for a subsample of respondents and collected actual voting data from another subsample, we focus here on vote intention rather than vote. More specifically, in our main models the dependent variable is whether or not the respondent scored 8 or more on the vote intention scale in contrast to all other vote intentions. ${ }^{48}$ This effectively excludes the behavioural components of voting, which are dependent on election day stimuli or 'companion effects' such as the benefits of walking to the polling station together. ${ }^{49}$ Fortunately, however, because a fraction of the USoc sample completed both the 'General Election' and the 'politics' modules, we are able to repeat the models (albeit with a much smaller sample) on reported vote (as well as vote intention). ${ }^{50}$ However, because of a large difference in sample size the main

45 Goldstein 2003; Jones 1997.

${ }^{46}$ Guo and Zhao 2000.

47 A multilevel model with a binary outcome can also be derived by assuming that there exists a latent continuous variable $y_{i j}^{*}$ underlying $\mathrm{y}_{i j}$. In simple terms, we know that $y_{i j}^{*}>0$ if $\mathrm{y}_{i j}=1$ and $y_{i j}^{*} \leq 0$ if $\mathrm{y}_{i j}=1$. So an equivalent multilevel model can be derived that is equivalent to Equation 1, where $y_{i j}^{*}=\beta_{0}+\beta_{1} x_{i j}+u_{j}+e_{i j}$.

${ }^{48}$ Respondents were asked on a scale from $0-10$ (where $0=$ no intention; $10=$ strongly intend to vote) whether they intended to vote in the general election. The distribution was highly skewed, removing any possibility of treating the variable as continuous; 48.2 per cent of those sampled stated that they strongly intended to vote (score of 10), whereas 64.4 per cent of the sample gave a response of 8 or more, a figure almost identical to the actual UK General Election turnout (65.1 per cent). Analysis after the election using the same likelihood to vote question was carried out using the 2010 British Election Study. This showed that while around 80 per cent of respondents scoring 8 or more actually voted, this figures drops for values of 7 or below. Consequently we use the 8-10 measure but also provide the results for vote intention (10) in Appendix Table A2. We found little or no differences between the two measures, with no changes in the significance of key or other control variables.

${ }^{49}$ Fieldhouse and Cutts 2012.

${ }^{50}$ We use the variance partition coefficient (VPC) to measure the proportion of the total residual variance that is attributable to the higher-level unit (in our case household). Where the response is binary (as in our case), there 
analyses focus on vote intention. It should be remembered that this effectively excludes factors that might account for the strength (or weakness) of the link between intention and behaviour. ${ }^{51}$ Using vote intention as the dependent variable is therefore likely to provide a conservative estimate of household effects. Models of actual vote with the reduced sample are reported in Appendix Table A1.

\section{Key Independent Variables}

To test the relational household component of social norms (Hypothesis 1), we include a measure of the civic duty of other members of the household alongside the standard civic duty measure. ${ }^{52}$ As an additional indicator and stricter control, we also include a variable measuring descriptive norms (whether 'most people around here usually vote in general elections'). To test the impact of relational expressive motivations (Hypothesis 2) - that is, that citizens who share a party identification with other members of their household will be more likely to vote - we include a combined measure of the partisan composition of the individual and household. This is coded as a categorical variable, Household Partisanship, which differentiates between sole partisans (individuals who are the only party identifier in the household), opposing partisans (where another household member has a different party identification to the respondent), shared partisans (where partisanship is shared with at least one member of the household) and nonpartisans. Single-person households are coded separately with a dummy variable and are not considered to score on household civic duty or shared partisanship. To ensure we do not conflate the effect of shared partisanship with the simple effect of partisanship, the reference category is 'sole partisan'.

As far as possible given the available data, we take account of internal and individual motivations to vote as set out in Table 1 . We include two indicators that reflect the internal social benefits of voting: civic duty and group benefits. The latter is defined as the extent to which people agree that 'voting is a good way to get benefits for groups that people care about, like pensioners and the disabled'. ${ }^{3}$ To reflect the existence of individual or egoist motivations to vote - those primarily driven by personal benefits or objectives - we include satisfaction gained from voting and personal feelings towards the most-favoured party. The latter is an indicator of egocentric expressive motives to vote. By including this at the individual level we can rule out the possibility that any differences between sole partisans and shared partisans are simply the result of differences in the strength of attachment to parties between the two groups (that is, that shared partisans are simply more partisan). ${ }^{54}$ The model also contains a number of

\section{(F'note continued)}

is no single measure of the VPC primarily because the level-1 variance is a function of the mean and is reliant on the strength of predictor models in the actual model. A common method is to treat the binary outcome as a latent continuous variable. We regard the underlying variable eij as a standard logistic distribution with a variance of 3.29 to compute the VPC. We use this method to calculate the VPC in the tables.

51 Azjen and Fishbain 1980.

${ }^{52}$ Civic duty is measured on a 1-5 scale from 'strongly disagree' to 'strongly agree' with the statement 'I would be seriously neglecting my duty as a citizen if I didn't vote.' Household duty is measured by whether or not at least one other member of the subject respondent's household agrees or strongly agrees (values 4 and 5) with this statement.

${ }^{53}$ Both of these variables are coded on a $1-5$ scale $(1=$ strongly disagree; $5=$ strongly agree $)$.

${ }^{54}$ Personal benefits: respondents were presented with the following statement: 'I feel a satisfaction when I vote' $(1=$ strongly disagree; $5=$ strongly agree). Feelings towards a party variable: 'On a scale from $0-10$ $(0$ means $=$ dislike; $10=$ strongly like $)$, how do you feel about the Labour/Conservative/Liberal Democrat Party?' The highest value was taken as a measure of feelings towards their most-favoured party. 
TAвLE 2 Consumption Benefits by Vote Intention (eight to ten) and Vote

\begin{tabular}{lcccc}
\hline \hline Variables & $\begin{array}{c}\text { Intend to } \\
\text { vote }(\%)\end{array}$ & $\begin{array}{c}\text { Do not intend } \\
\text { to vote }(\%)\end{array}$ & Voted $(\%)$ & $\begin{array}{r}\text { Did not } \\
\text { vote }(\%)\end{array}$ \\
\hline Household Civic Duty & 72.3 & 27.7 & 82.2 & 17.8 \\
Individual Civic Duty* & 83.5 & 16.5 & 86.3 & 13.7 \\
Descriptive Norms* & 72.7 & 27.3 & 81.1 & 18.9 \\
No Party Identification & 56.9 & 43.1 & 60.6 & 39.4 \\
Opposing Partisanship & 78.7 & 21.3 & 85.7 & 14.3 \\
Sole Partisanship & 71.7 & 28.3 & 79.0 & 21.0 \\
Shared Partisanship & 84.4 & 15.6 & - & 11.5 \\
Overall Vote Intention & 64.4 & 35.6 & 75.2 & - \\
Overall Vote & - & - & 1,657 & 24.8 \\
N & 8,337 & 8,337 & & 1,657 \\
\hline
\end{tabular}

Note: for individual civic duty and descriptive norms, we use a combination of agree and strongly agree.

other control variables including external efficacy, (the perceived personal influence on the election outcome); political costs (though, as mentioned above, we do not have a measure of the social dimension of political costs); political interest; and conventional socio-economic variables including sex, age and education. ${ }^{55}$

\section{ANALYSIS}

Table 2 provides some preliminary evidence that the two key variables - household civic duty and household partisanship - are associated with vote intention and vote. The intention to vote rate for respondents living in households where another household member scores four or more out of five on civic duty is just over 72 per cent, compared to around 64 per cent in the sample as a whole. For vote, the rate for 'dutiful households' is 82 per cent compared to 75 per cent for the overall sample. The presence of other household members who share the same party identification with the respondent also has a strong bivariate relationship with vote intention. Just over 84 per cent of citizens who live in a household where there is another member who identifies with the same party said they intended to vote, compared to 72 per cent for sole identifiers in a household. The equivalent figure for vote is 89 per cent compared to 79 per cent for sole identifiers. Because the rate for shared partisans exceeds that for sole partisans, we can be reasonably confident that it is not attributable to individual-level partisanship, but to the sharing of partisanship with social intimates. Interestingly, however, respondents who live with an identifier of a different party are also more likely to vote than sole partisans -7 per cent more likely to intend to vote and 6.7 per cent more likely to vote - suggesting that there are some effects of cross-pressures in the household for both intention and vote. This suggests that while partisan disagreement may be detrimental for turnout when compared to agreement, ${ }^{56}$

55 Perceived political influence: 'On a scale from $0-10$, where $0=$ very unlikely and $10=$ very likely, how likely is it that your vote will make a difference in terms of which party wins the election in this constituency at the next general election?' Political costs: 'It takes too much time and effort to be active in politics and public affairs' ( $1=$ strongly disagree; $5=$ strongly agree). For political interest: 'How interested would you say you were in politics' $(1=$ not at all interested; $5=$ very interested $)$.

${ }^{56}$ Mutz 2006. 
even disagreeable partisan views among other household members may be more favourable to turnout than a complete lack of partisan attachment. This may be attributable to the impact of stronger social norms of voting among partisans of all parties, which we address in the multivariate analysis below.

Although Table 2 provides some prima facie evidence, it is more than likely that many of these differences are due to other sources of homogeneity within households. As well as being more likely to interact with and influence each other, people who live in the same household tend to be more alike in many ways, including their socio-economic characteristics and political interest. The process of interpersonal influence may therefore lead to household correlations in other attitudes or interests. In the following multivariate multilevel model of vote intention we therefore control for these effects.

Table 3 shows multilevel logistic models of vote intention for alternative model specifications. Model 1 shows the coefficients for the norms model including household relational norms (household civic duty), descriptive norms and personal normative beliefs (individual civic duty) as well as all the control variables discussed above. As hypothesized, we find that household civic duty has a significant positive effect on vote intention even when allowing for individual civic duty and descriptive norms of voting (both of which are also strongly significant). Reassuringly, the vote models (Appendix Table A1) confirm the findings of the vote intention models, with slightly larger effects for relational norms. Model 1 also suggests that individual benefits - personal efficacy and satisfaction from voting - are all significant and in the direction expected. As expected, individual-level civic duty has a strong positive impact on intention, although group benefits do not. Political interest, age and education are also significant, with older, highly educated individuals and those most interested in politics more likely to intend to vote.

Model 2 introduces relational expressive motives while removing the normative motives. As hypothesized, respondents who share a party identification with another household member are significantly more likely to intend to vote than sole identifiers. This is confirmed in the vote model (Table A1). Non-identifiers are much less likely to intend to vote, which, when compared to the base category (sole identifiers), indicates the impact of individual-level party identification. However, in the vote intention model, opposing identifiers are equally likely to vote as shared identifiers, suggesting the critical factor may be shared norms and expectations of participation rather than enhanced expressive benefits via common partisanship. This possibility is explored further in Model 3, which simultaneously includes relational normative and expressive motives. It should be noted, however, that unlike shared identification, opposing identification does not have a significant effect in the vote model (Table A1).

When norms and expressive motives are included together (Model 3), we find that shared partisanship is still significant, while opposing identification is marginally insignificant, although the magnitude of the effects are not greatly different. ${ }^{57}$ The effect for shared identification is confirmed when positive vote intention is defined as scores of 10 only (Table A2), though in this model opposing identification is also significant. In the reported vote model (Table A1) both effects are marginally insignificant although the magnitude is very similar, reflecting the reduced sample size. The relative effect sizes for the vote intention model are illustrated in Figure 1, which shows the predicted probabilities for different combinations of

\footnotetext{
57 In the vote model the effect sizes are similar, but due to a small $\mathrm{N}$ are statistically insignificant in the full model. Because it is likely that the effect of shared partisanship may be mediated by enhanced expressive benefits, we ran an alternate model without party feeling scores (Model 3a). Shared partisanship is indeed significant when this is removed, suggesting partial mediation.
} 
TAв LE 3 Multilevel Logistic Model of Vote Intention (eight to ten)

\begin{tabular}{|c|c|c|c|}
\hline Variables & $\begin{array}{c}\text { Model } 1 \text { VI } \\
\text { (Norms) } \beta \text { (SE) }\end{array}$ & $\begin{array}{c}\text { Model } 2 \mathrm{VI} \\
\text { (Expressive) } \beta \text { (SE) }\end{array}$ & $\begin{array}{c}\text { Model } 3 \text { VI (Full } \\
\text { model) } \beta \text { (SE) }\end{array}$ \\
\hline Constant & $\begin{array}{c}-5.61^{*} \\
(0.24)\end{array}$ & $\begin{array}{c}-3.35^{*} \\
(0.21)\end{array}$ & $\begin{array}{c}-5.33^{*} \\
(0.26)\end{array}$ \\
\hline \multicolumn{4}{|l|}{$\begin{array}{l}\text { Expressive social } \\
\text { Household Partisanship } \\
\quad \text { (base = sole identifier) }\end{array}$} \\
\hline Non-identifier & - & $\begin{array}{c}-0.64 * \\
(0.10)\end{array}$ & $\begin{array}{c}-0.59 * \\
(0.08)\end{array}$ \\
\hline Opposing identification & - & $\begin{array}{l}0.57^{*} \\
(0.19)\end{array}$ & $\begin{array}{c}0.36 \\
(0.19)\end{array}$ \\
\hline Shared identification & - & $\begin{array}{l}0.56^{*} \\
(0.11)\end{array}$ & $\begin{array}{r}0.45^{*} \\
(0.11)\end{array}$ \\
\hline \multicolumn{4}{|l|}{ Expressive individual } \\
\hline Feelings Towards Party & - & $\begin{array}{c}0.18^{*} \\
(0.02)\end{array}$ & $\begin{array}{c}0.17 * \\
(0.02)\end{array}$ \\
\hline \multicolumn{4}{|l|}{ Personal normative } \\
\hline Civic Duty & $\begin{array}{l}0.82^{*} \\
(0.04)\end{array}$ & - & $\begin{array}{l}0.78^{*} \\
(0.04)\end{array}$ \\
\hline \multicolumn{4}{|l|}{ Relational norms } \\
\hline Civic Duty (Household) & $\begin{array}{l}0.52^{*} \\
(0.08)\end{array}$ & - & $\begin{array}{r}0.33^{*} \\
(0.09)\end{array}$ \\
\hline Descriptive norms & $\begin{array}{r}0.25^{*} \\
(0.04)\end{array}$ & - & $\begin{array}{l}0.25^{*} \\
(0.04)\end{array}$ \\
\hline \multicolumn{4}{|l|}{ Individual benefits } \\
\hline Personal Influence & $\begin{array}{c}0.14^{*} \\
(0.01)\end{array}$ & $\begin{array}{c}0.12^{*} \\
(0.01)\end{array}$ & $\begin{array}{c}0.09^{*} \\
(0.01)\end{array}$ \\
\hline Satisfaction & $\begin{array}{l}0.54^{*} \\
(0.04)\end{array}$ & $\begin{array}{l}0.74^{*} \\
(0.04)\end{array}$ & $\begin{array}{l}0.45^{*} \\
(0.04)\end{array}$ \\
\hline \multicolumn{4}{|l|}{ Group benefits } \\
\hline Group Benefits & $\begin{array}{c}0.03 \\
(0.04)\end{array}$ & $\begin{array}{c}0.08^{*} \\
(0.04)\end{array}$ & $\begin{array}{r}-0.00 \\
(0.04)\end{array}$ \\
\hline \multicolumn{4}{|l|}{ Costs } \\
\hline Political Costs & $\begin{array}{c}-0.18 * \\
(0.04)\end{array}$ & $\begin{array}{c}-0.12 \\
(0.04)\end{array}$ & $\begin{array}{c}-0.19 * \\
(0.04)\end{array}$ \\
\hline \multicolumn{4}{|c|}{$\begin{array}{l}\text { Household size } \\
\quad \text { (Base = Single-Person Households) }\end{array}$} \\
\hline Two-Person Households & $\begin{array}{r}-0.18^{*} \\
(0.09)\end{array}$ & $\begin{array}{c}-0.07 \\
(0.08)\end{array}$ & $\begin{array}{c}-0.28^{*} \\
(0.09)\end{array}$ \\
\hline Three-Person Households & $\begin{array}{r}-0.44^{*} \\
(0.12)\end{array}$ & $\begin{array}{r}-0.42 * \\
(0.11)\end{array}$ & $\begin{array}{r}-0.66^{*} \\
(0.13)\end{array}$ \\
\hline \multicolumn{4}{|l|}{ Controls } \\
\hline Political Interest & $\begin{array}{l}0.68^{*} \\
(0.07)\end{array}$ & $\begin{array}{r}0.54^{*} \\
(0.07)\end{array}$ & $\begin{array}{r}0.42 * \\
(0.07)\end{array}$ \\
\hline Gender (Male) & $\begin{array}{c}0.03 \\
(0.06)\end{array}$ & $\begin{array}{c}-0.01 \\
(0.06)\end{array}$ & $\begin{array}{c}0.04 \\
(0.07)\end{array}$ \\
\hline \multicolumn{4}{|l|}{ Age $($ Base $=$ Middle 30-44) } \\
\hline Young Age <25 & $\begin{array}{l}-0.10 \\
(0.09)\end{array}$ & $\begin{array}{r}-0.28^{*} \\
(0.09)\end{array}$ & $\begin{array}{c}-0.17 \\
(0.09)\end{array}$ \\
\hline Mid/Older Age 45-59 & $\begin{array}{l}0.40^{*} \\
(0.09)\end{array}$ & $\begin{array}{r}0.38^{*} \\
(0.08)\end{array}$ & $\begin{array}{r}0.36^{*} \\
(0.09)\end{array}$ \\
\hline Old Age 60 plus & $\begin{array}{l}0.57^{*} \\
(0.10)\end{array}$ & $\begin{array}{l}0.71^{*} \\
(0.10)\end{array}$ & $\begin{array}{l}0.53^{*} \\
(0.10)\end{array}$ \\
\hline
\end{tabular}


TABLE $3 \quad$ (Continued)

\begin{tabular}{lccc}
\hline \hline Variables & $\begin{array}{c}\text { Model 1 VI } \\
\text { (Norms) } \beta \text { (SE) }\end{array}$ & $\begin{array}{c}\text { Model 2 VI } \\
\text { (Expressive) } \beta \text { (SE) }\end{array}$ & $\begin{array}{c}\text { Model 3 VI (Full } \\
\text { model) } \beta \text { (SE) }\end{array}$ \\
\hline Degree & 0.05 & $0.17^{*}$ & 0.04 \\
& $(0.07)$ & $(0.07)$ & $(0.07)$ \\
Random effects & & & \\
Between-Household Variance & $0.61^{*}$ & $0.68^{*}$ & $0.59^{*}$ \\
& $(0.09)$ & $(0.09)$ & $(0.09)$ \\
Variance Partition Coefficient & 0.16 & 0.17 & 0.15 \\
Joint Chi-Square Test (1 Df) & $44.21^{*}$ & $56.41^{*}$ & $39.11^{*}$ \\
N & 8,337 & 8,337 & 8,337 \\
\hline \hline
\end{tabular}

Note: significant at $<0.05$ level. The estimation method is penalized quasi-likelihood.

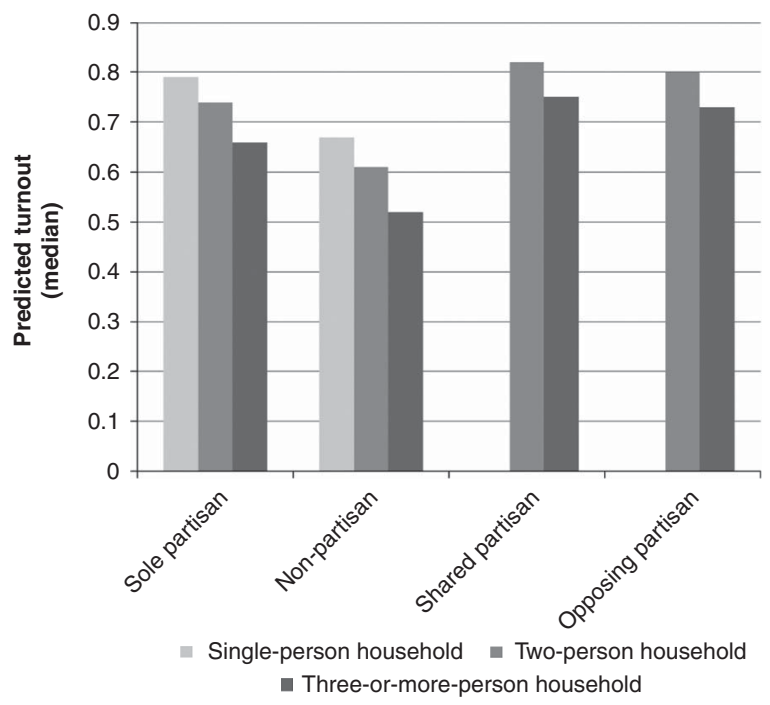

Fig. 1. Predicted probabilities by household partisanship

household partisanship by household size with other variables set at their median values. As well as demonstrating the lower propensity of non-partisans to vote, we see that in multiplevoter households, there is very little difference between shared and opposing partisans, but both have higher levels of turnout intention than individuals who are the only party identifiers in the household. The enhanced turnout where party identification is shared between household members is consistent with Hypothesis 2, derived from the theoretical expectations of expressive voting - that having a shared party identification with social intimates should enhance the motivation to vote. However, since we see a similar effect for opposing partisans (as noted above), this suggests that shared norms and mutually supporting behaviour may be a more important explanation.

This interpretation is supported by Figure 2, which shows the effect sizes for household duty by household size derived from Model 3, providing clear support for Hypothesis 1. Civic duty of household members has a large and significant impact on vote intention over and above the 


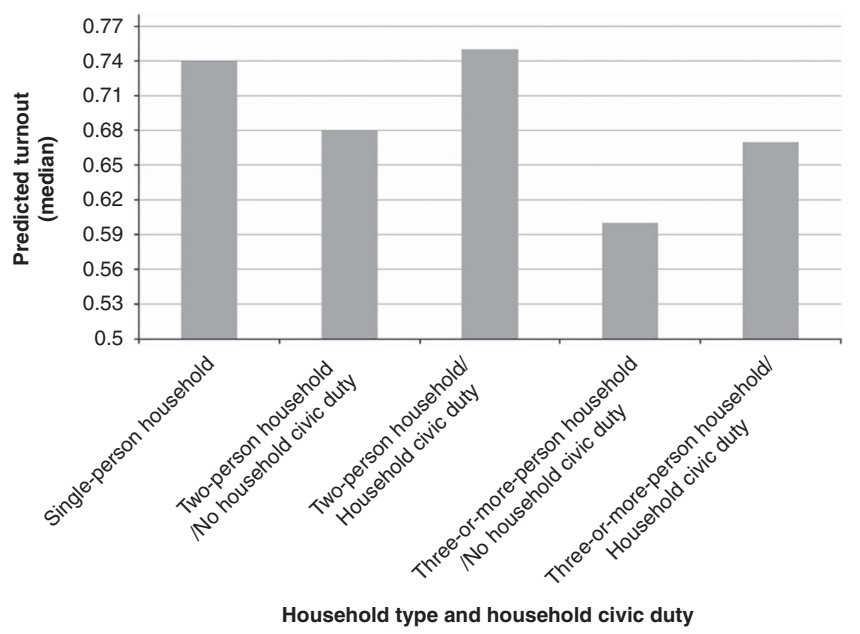

Fig. 2. Predicted probabilities by household civic duty

respondents' own level of civic duty and regardless of household size. For example, persons living in two-elector households in which other members regard it a duty to vote have a predicted probability of voting of 0.75 , compared to 0.68 for similar people living with other electors who do not regard voting as a duty. Moreover, turnout in two-elector households in which other members do not regard it a duty to vote is considerably lower than in single-voter households. However, for persons living in two-elector households where other members do regard it a duty to vote, turnout is slightly higher than that of similar people in single-elector households. This is confirmed in the reported vote model, which has a slightly larger effect for household civic duty than the vote intention model (Table A1, Model 3). This provides support for the hypothesis that social norms that are externally validated and enforced through close social relationships are important drivers of turnout. This effect is over and above the role of internalized social norms as reflected in individual-level attitudes towards voting. In other words, it is not necessarily sufficient to believe in a duty to vote; it is also important to be connected to others who also believe in that duty.

\section{CONCLUSION}

In this article we have set out the basis for a relational theory of voting that incorporates external-selective consumption motivations. We emphasize that relational selective consumption benefits contain both normative and expressive elements that are underpinned by shared partisan identity and interpersonal influence. Our aim has been to develop a theoretical framework that accounts for the tendency of families, households and networks to vote together - that is, that when one person in a family turns out to vote, on the whole, others do too. More generally, our contention is that voting is not only an act driven by a motivation to achieve political goals, but a social activity that, like other social activities, reflects many circumstantial factors and influences, defined by the voter's social situation. The voting decision is a multilevel process in which the turnout behaviour of voters sharing the same context is correlated. This correlation arises because within a household, network or locale, each individual's incentive to participate is connected to others through channels of interpersonal influence, shared identities and anticipated interactions. 
Building on this theoretical approach, we identified household voting norms and expressive voting as determining the key relational selective consumption benefits that might help explain household clustering in turnout (Hypothesis 2). Using household hierarchical data, we have demonstrated that the social norms of other household members are important factors in explaining turnout, even when allowing for the role of internalized social norms (or civic duty) at the individual level (Hypothesis 1). Secondly, in accordance with expectations of expressive theories of voting, ${ }^{58}$ having a shared party identification with social intimates does indeed enhance the motivation to vote. However, contrary to expectations of theories of disagreement and ambivalence, ${ }^{59}$ there was some evidence that even opposing partisanship is associated with higher levels of turnout. This strengthens the case that social norms are particularly important, a claim supported by the combined model of relational norms and expressive motives on voter turnout.

To varying degrees, each of the motivations to vote can be linked directly to membership of social networks or social groups. In this article we have focused on relational factors that explain voting intention. We have argued that these relational factors are distinct from internal social influences in that they require interaction (or anticipated future interactions) with social intimates and are not necessarily manifested in personal normative beliefs. For example, even where an individual expresses belief in the norm of voting, the pressure of social intimates sharing that norm - and thereby potentially holding the individual to account - had an independent and additional effect on the likelihood of voting. This is likely to be especially true in households where members can observe each other's voting behaviour. We have shown that contextually driven variations in the relational consumption benefits of voting - shared party identification and household norms - can help explain both why citizens vote and why turnout is socially clustered. Moreover, although it is beyond the scope of this article, the relational theory proposed here has important implications for the study of turnout behaviour over the life course - ageing, ${ }^{60}$ life-cycle effects, ${ }^{61}$ and how voting is subject to habit or inertia ${ }^{62}$ - and by extension to understanding long-term political change. Future research should test our social-dynamic theory of voting where the social context at any one point in the life course can have spill-over effects on electoral participation later in life. Key life events such as leaving home, receiving higher education, getting a job, moving home, getting married, having children, retirement and widowhood are all associated with changes in the extent to which citizens live and interact with other voters or non-voters, which may have lasting effects on turnout. In other words, turnout patterns over the life course are (in part) the product of changing relational selective consumption costs and benefits, and inertia.

\section{REFERENCES}

Abrams, Samuel, Torben Iversen, and David Soskice. 2011. Informal Social Networks and Rational Voting. British Journal of Political Science 41 (2):229-57.

Ajzen, Icek, and Martin Fishbein. 1980. Understanding Attitudes and Predicting Social Behaviour. Upper Saddle River, NJ: Prentice Hall.

Aldrich, John H. 1993. Rational Choice and Turnout. American Journal of Political Science 37 (1): 246-78.

Barry, Brian M. 1970. Sociologists, Economists and Democracy. London: Sollier-Macmillan.

58 Schuessler 2000.

59 Mutz 2006.

60 Bhatti and Hansen 2012; Goerres 2007; Smets 2012.

61 Jennings, Stoker, and Bowers 2009; Plutzer 2002.

62 Cutts, Fieldhouse, and John 2009; Denny and Doyle 2009; Dinas 2012. 
Bendor, Jonathan, Daniel Diermeier, and Michael Ting. 2003. A Behavioral Model of Turnout. American Political Science Review 97 (2):261-80.

Berelson, Bernard R., Paul F. Lazarsfeld, and William N. McPhee. 1954. Voting. Chicago, IL: The University of Chicago Press.

Bhatti, Yosef, and Kasper M. Hansen. 2012. Retiring from Voting: Turnout Among Senior Voters. Journal of Elections, Public Opinion and Parties 22 (4):479-500.

Bicchieri, Christina. 2015. Norms in the Wild. Cambridge: Cambridge University Press.

Blais, Andre. 2000. To Vote or Not to Vote? The Merits and Limits of Rational Choice Theory. Pittsburg, PA: University of Pittsburgh Press.

Blais, Andre, and Christopher H. Achen. 2010. Taking Civic Duty Seriously: Political Theory and Voter Turnout. Available at https://www.princeton.edu/csdp/events/Achen031110/Achen031110.pdf, accessed 17 July 2015.

Bond, Robert M., Christopher J. Fariss, Jason J. Jones, Adam D.I. Kramer, Cameron Marlow, Jaime E. Settle, and James H. Fowler. 2012. A 61-million-person Experiment in Social Influence and Political Mobilization. Nature 489:295-98.

Brennan, Geoffrey, and Loren E. Lomasky. 1993. Democracy and Decision. Cambridge: Cambridge University Press.

Coleman, James S. 1990. Foundations of Social Theory. Cambridge, MA: Harvard University Press.

Converse, P.E. 1962. Information flow and the stability of partisan attitudes. Public opinion quarterly 26 (4):578-99.

Cutts, David, and Edward. Fieldhouse. 2009. What Small Spatial Scales are Relevant as Electoral Contexts for Individual Voters? The Importance of the Household on Turnout at the 2001 General Election. American Journal of Political Science 53 (3):726-39.

Cutts, David, Edward Fieldhouse, and Peter John. 2009. Is Voting Habit Forming? The Longitudinal Impact of a GOTV Campaign in the UK. Journal of Elections and Public Opinion and Parties 19 (3):251-63.

Denny, Kevin, and Orla Doyle. 2009. Does Voting History Matter? Analysing Persistence in Turnout. American Journal of Political Science 53 (1):17-35.

Dinas, Elias. 2012. The Formation of Voting Habits. Journal of Elections and Public Opinion and Parties 22 (4):431-56.

Dowding, Keith, Peter John, and Daniel Rubenson. 2012. Geographic Mobility, Social Connections and Voter Turnout. Journal of Elections, Public Opinion \& Parties 22 (2):109-22.

Downs, A. 1957. An Economic Theory of Democracy. New York: Harper Row.

Fieldhouse, Edward, and David Cutts. 2012. The Companion Effect: Household and Local Context and the Turnout of Young People. Journal of Politics 74 (3):856-69.

Fiorina, Morris P. 1976. The Voting Decision: Instrumental and Expressive Aspects. The Journal of Politics 38 (2):390-413.

Fowler, James H. 2005. Turnout in a Small World. In Social Logic of Politics, edited by A. Zuckerman, 269-87. Philadelphia, PA: Temple University Press.

Franklin, Mark N. 2004. Voter Turnout and the Dynamics of Electoral Competition in Established Democracies Since 1945. Cambridge: Cambridge University Press.

Gerber, Alan S., Donald P. Green, and Christopher W. Larimer. 2010. An Experiment Testing the Relative Effectiveness of Encouraging Voter Participation by Inducing Feelings of Pride or Shame. Political Behavior 32 (3):409-22.

Goerres, Achim. 2007. Why are Older People More Likely to Vote? The Impact of Ageing on Electoral Turnout in Europe. British Journal of Politics and International Relations 9 (1):90-121.

Goldstein, Harvey. 2003. Multilevel Statistical Models, 3rd Edition, London: Hodder Arnold.

Goodin, Robert E., and Kevin W. S. Roberts. 1975. The Ethical Voter. American Political Science Review 69:926-28.

Green, Donald P., and Alan S. Gerber. 2010. Introduction to Social Pressure and Voting: New Experimental Evidence. Political Behaviour 32:331-36. 
- 2010. Introduction to Social Pressure and Voting: New Experimental Evidence. Political Behavior 32 (3):331-36.

Green, Donald P., Bradley Palmquist, and Erik Schickler. 2002. Partisan Hearts and Minds: Political Parties and the Social Identities of Voters. New Haven, CT: Yale University Press.

Guo, Guang, and Hongxin Zhao. 2000. Multilevel Modelling for Binary Data. Annual Review of Sociology 26:441-62.

Harsanyi, John C. 1980. Rule Utilitarianism, Rights, Obligations and the Theory of Rational Behavior. Theory and Decision 12:115-33.

Huckfeldt, Robert, and John Sprague. 1995. Citizens, Politics and Social Communication: Information and Influence in an Election Campaign. Cambridge: Cambridge University Press.

Jennings, M. Kent, Laura Stoker, and Jake Bowers. 2009. Politics Across Generations: Family Transmission Re-Examined. Journal of Politics 71 (3):782-99.

Jennings, M. Kent, and Richard G. Niemi. 1981. Generations and Politics: A Panel Study of Young Adults and Their Parents. Princeton, NJ: Princeton University Press.

Jones, Kelvyn. 1997. Multilevel Approaches to Modelling Contextuality: From Nuisance to Substance in the Analysis of Voting Behaviour. In Places and People: Multilevel Modelling in Geographical Research, Netherlands Geographical Studies 227, edited by G. Westert and R. Verhoeff, 19-43. Amsterdam: Royal Dutch Geographical Society.

Knack, Stephen. 1992. Civic Norms, Social Sanctions, and Voter Turnout. Rationality and Society 4:133-56.

Lazarsfeld, P., B. Berelson, and H. Gaudet. 1944. The People's Choice, 1st Edition, New York: Columbia University Press.

McClurg, Scott D. 2003. Social Networks and Political Participation: The Role of Social Interaction in Explaining Political Participation. Political Research Quarterly 56 (4):449-64.

Morton, Rebecca B. 1991. Groups in Rational Turnout Models. American Journal of Political Science 35 (3):758-76.

Mutz, Diana C. 2006. Hearing the Other Side: Deliberative Versus Participatory Democracy. Cambridge: Cambridge University Press.

Nickerson, David. 2008. Is Voting Contagious? Evidence from Two Field Experiments. American Political Science Review 102 (1):49-57.

Panagopoulas, Costas. 2010. Affect, Social Pressure and Prosocial Motivation: Field Experimental Evidence of the Mobilizing Effects of Pride, Shame and Publicizing Voting Behaviour. Political Behaviour 32 (3):369-86.

Plutzer, Eric. 2002. Becoming a Habitual Voter: Inertia, Resources, and Growth in Young Adulthood. American Political Science Review 96:41-56.

Riker, William H., and Peter C. Ordeshook. 1968. A Theory of the Calculus of Voting. American Political Science Review 62 (1):25-42.

Rolfe, Meredith. 2012. Voter Turnout: A Social Theory of Political Participation. Cambridge: Cambridge University Press.

Rosenstone, Steven, and John M. Hansen. 1993. Mobilization, Participation and Democracy in America. New York: Macmillan.

Schelling, T.C. 1978. Micromotives and Microbehaviour. New York: W.W. Norton.

Schuessler, Alexander A. 2000. A Logic of Expressive Choice. Princeton, NJ: Princeton University Press.

Sinclair, B. 2012. The Social Citizen: Peer Networks and Political Behavior. Chicago Studies in American Politics: University of Chicago Press, Chicago.

Smets, Kaat. 2012. A Widening Generational Divide? The Age Gap in Voter Turnout Through Time and Space. Journal of Elections, Public Opinion and Parties 22 (4):407-30.

Uhlaner, Carole J. 1989. Rational Turnout: The Neglected Role of Groups. American Journal of Political Science 33 (2):390-422.

Zuckerman, Alan, Josip Dasovic, and Jennifer Fitzgerald. 2007. Partisan Families: The Social Logic of Bounded Partisanship in Germany and Britain. New York: Cambridge University Press. 